\title{
Notas sobre algunas mujeres del Collasuyu (siglos XV al XVIII)
}

\author{
Margarita E. Gentile Lafaille*
}

\section{Resumen}

Este artículo reúne datos acerca de mujeres poco conocidas en la historia andina cuya actividad fue parte de decisiones políticas.

\section{Palabras clave}

Historia colonial - juegos de tablero - área andina argentina - aclla - curaca - Folklore.

\begin{abstract}
: politics.

Key words

Colonial History - table games - Northwest Argentine - aclla - curaca - Folklore.
\end{abstract}

This article get together some data about less known Andean women whose activity take important part in

* Investigador CONICET - Museo de La Plata, Profesor titular ordinario - Instituto Universitario Nacional del Arte-Folklore. Correo electrónico: margagentile@yahoo.com.ar 


\section{Introducción}

Desde mediados del siglo XIX las mujeres de todas las épocas y lugares vienen siendo particular objeto de estudio, dando lugar a una bibliografía abrumadora, diversa y abarcativa de casi todo lo relacionado con ellas. Pero acerca de las mujeres andinas, la documentación colonial está dispersa, tal vez porque el encuadre jurídico hispano las consideraba, al igual que a las españolas, como incapaces; en consecuencia no fueron el centro de ningún acto administrativo, salvo las de la elite, sobre las que se concentraron los estudios (Espinoza Soriano 1976; Lyon 1978; Hocquenghem \& Lyon 1980; Ellefsen 1982; Varón Gabai 1993; Rostworowski 1978, inter alia)

Con el propósito de ampliar y matizar lo que se sabe acerca de las mujeres del Collasuyu entre los siglos XV y XVIII, reunimos aquí datos sobre algunas de las que no trascendieron a la historia andina más allá de algunas citas documentales, no obstante lo cual su actividad estuvo en sintonía con complicadas redes sociopolíticas.

\section{Las aclla Guayro}

La institución de gente elegida y preparada para fines determinados (mujeres y hombres), en lo que concierne al Tahuantinsuyu data del gobierno de Pachacutec; según algunos cronistas, las distintas clases de mujeres y las tareas que realizaban hacia fuera del aillu se basaba en una clasificación por edades y tiempo de permanencia en el aclla huaci (Betanzos [1551] 1987: 50, 116; Cieza de León [1553] 1967; Pizarro, [1571] 1978: 93-96; Guamán Poma, [1613] 1987: 248,
296; Murúa [1613?] 1993: 205, 231; entre muchos otros).

Había casas para acllas fuera del Cusco y, hasta cierto punto su trabajo era una forma de mita y, si bien las más bonitas se destinaban a esposas de los curacas aliados, parece que la educación al modo cusqueño no era dispensada igualmente a todas ellas ${ }^{1}$.

En una publicación anterior vimos que una de estas acllas pasó a la historia andina relacionada con una forma de juego / oráculo: la pichca (Gentile, 1998, 2003).

En algún punto de la cronología relativa, la pichca dejó de ser un oráculo, se transformó parcialmente en pasatiempo y sus jugadores ya no eran miembros de la elite. Los andinos habían inventado juegos similares a los europeos porque usaban un dado (la pichca) para indicar los tantos que debían avanzar las fichas (Cobo, [1653] 1968 II: 269-270); con la pichca también se podía jugar chuncara: “... de cinco hoyos pequeños cavados en alguna piedra llana o en tabla: jugábanlo con frísoles de varios colores, echando el dado, y como caía la suerte, los mudaban por sus casas hasta llegar al término; la primera casa valía diez, y las otras iban creciendo un denario hasta la quinta, que valía cincuenta.". Con los mismos elementos también se jugaba tacanaco: "... como el juego de las tablas.", es decir, similar al "tres en raya" o alquerque, con nueve escaques cuyas fichas se movían según lo que marcaba el dado; también con un dado se jugaban aucay, halankolasitha y hunkusitha (Bertonio [1612] 1879; Cobo [1653] 1968 II: 270; Gonçalez Holguin [1608] 1952: 551; Murua [1613] 1986; Holm 1958). ${ }^{2}$

\footnotetext{
${ }^{1}$ Para poder establecer las diferencias - si las hubo- entre aclla y mamacona, habría que compulsar lo dicho por los testigos presenciales, es decir, tomar en cuenta el contexto ya que cabe la posibilidad de que los cronistas hayan usado dichas voces indistintamente; por otra parte, los plurales son acllacuna y mamacuna, fuera de lo dicho por Alberti Manzanares, 1986: 155. Lo mismo vale para el uso indistinto de aclla y guarme, cuando se habla de ellas en contextos de mujeres seleccionadas para fines determinados.

2 "Iugar al alquerque. Ttaptanacuni. / Iuego de alquerque. Ttaptana. / Iugar a la pichcca. Pichccacuni." (Gonçalez Holguin, [1608] 1952: 551). Es decir, tacanaco y taptana eran el mismo juego. Sobre este tema, la persona que leyó mi trabajo para esta Revista decía: "... el tablero ilustrado por Guamán Poma tiene muchas semejanzas con el juego de Alquerque de doce, que antiguamente era jugado en el Reino de Castilla y Granada (Westerveld 2004: 717)”.
} 
Había "otros [juegos] menos principales, como eran el llamado apaytalla, puma ${ }^{3}$ y otros." (Cobo, [1653] 1968 II: 270). Estos dos tendrían correspondencia con el registro etnográfico; el primero parece que era similar al shuká que jugaban los chorotí del Chaco argentino a mediados del siglo $\mathrm{XX}$ : se echaban cuatro tablitas que tenían dibujos en una cara, y la suerte máxima se obtenía cuando dos de ellas caían formando un aspa; el tablero era un semicírculo con huecos por donde corrían las fichas de ambos contendientes (Vivante, 1944: 214; Gentile 1998; 1999: 311); compartimos la opinión de Romero sobre que apaytalla tendría un registro prehispánico en algunos dibujos sobre alfarería Moche (Donnan \& McClelland 1999: 115, 116, 172, 269-274). En cuanto a puma, como juego, le dedicaremos el siguiente acápite.
Volviendo a nuestra aclla, con relación a las consecuencias sociopolíticas de los resultados de los juegos en el Cusco, en tiempo de Topa Inca Yupanqui, se jugaba a la pichca y los ayllos ; en dos oportunidades estuvo presente Guayro, una de las mujeres de este Inca, quien influyó decisivamente en el resultado quedando su nombre como el del as del juego de la pichca.

Acerca de su nombre, sin embargo tenemos que "Huayru, cierta nación, de indios, en esta tierra" (Anónimo [1586] 1951: 51); de ellos contaba Ramos Gavilán que un indio Canche estaba casado con una india de Copacabana, del ayllo Guayro; luego que Topa Inca asentó mitimaes en la región y estableció los santuarios en las islas ${ }^{6}$, los de Yunguyo, ayudados por lupacas y pacajes, trataron de reconquistar la isla Titicaca. Durante la batalla, murió el indio canche pero su

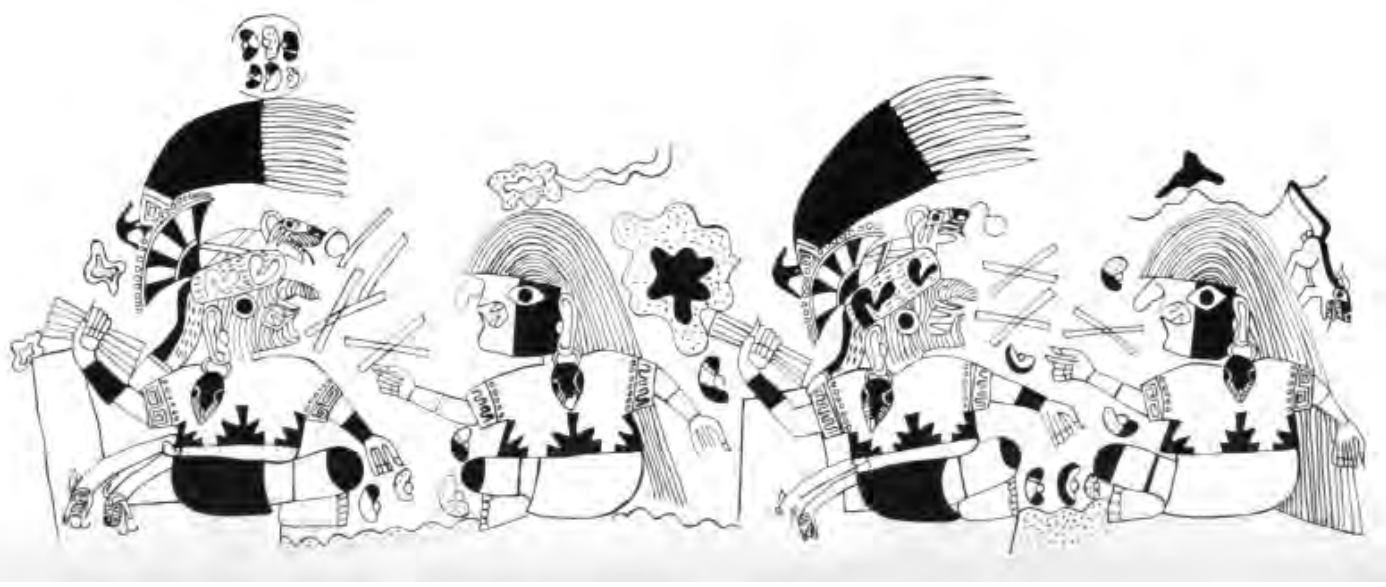

Figura 1. Uno de los muchos dibujos sobre alfarería mochica donde se ven dos personajes enfrentados portando y rodeados de los elementos usados también en el juego de apaitalla incaico y en el shuká del siglo $X X$. Uno de ellos tiene las tablillas en la mano en tanto que en el fondo de la figura y arriba están las mismas formando aspa, que es la suerte máxima en tanto que en medio de los jugadores se ven los frijoles usados como fichas del oráculo / juego. Los personajes pueden totalmente humanos o no. Según Donnan $\mathcal{G}$ McClelland, 1999: 115).

\footnotetext{
3 "Puma. Vnjuego de indios. / Pumani. Ingar a este juego. / Pumani. Caçar y matar las fieras a otros animales." (Gonçalez Holguin, [1608] 1952: 295).

4 Este último consistía en tirar al aire una serpiente de lana y atraparla con los ramales de los ayllos (boleadoras).

5 Canas y Canchis fueron tradicionales aliados de los cusqueños.

6 Esto significaba, según el mito que compartían los cusqueños con los habitantes del Collao, que el Inca se apropiaba del lugar donde había salido el Sol por primera vez.
} 
mujer consiguió sostener el asalto hasta que llegaron los refuerzos, y así los aliados del Cusco lograron vencer a los collas. En nuestra opinión, este indio de Canche era probablemente un curaca de mitmacuna, yanacona, a quien el Inca había dado en matrimonio una aclla guayro; sus nombres indígenas no los conocemos.

Esta actitud de Guayro al frente de los mitmacuna tras la muerte de su esposo, es uno entre otros datos acerca de mujeres dispuestas a defenderse por las armas; la cacica de Chocos Cachona sostuvo un sector del Cusco cuando los chanca trataron de invadir la ciudad; Betanzos decía que en las exequias de Pachacutec unas mujeres vestidas de hombres cantaban alrededor de la plaza del Cusco; del área andina argentina hay una placa de bronce de época incaica con dos personajes tras sendos escudos con dibujos de senos y una banda vertical en zig-zag (González 1977: fig 319) que en una cerámica de la misma época (en sentido amplio) está dibujada sobre el cuerpo de una parturienta (ibid. fig. 80) y en otra vasija amarilla y rojo (colores relacionados con capacocha, Gentile 1996), sobre el cuerpo de una mujer claramente definida a pesar de la estilización (ibid. fig. 151); es decir, la banda vertical en zig-zag identifica a las mujeres y tras los escudos ihay mujeres, u hombres que cuidan mujeres?

Volviendo a Guayro, tras la batalla, Topa Inca la tomó por mujer y, según el mismo cronista, era una de sus preferidas y lo acompañaba siempre; esta actitud del Inca refuerza lo dicho acerca de que se trataba de una aclla guayro, pero cabe preguntarse si, tras su viudez, hubiera podido regresar al acllahuasi.

La otra escena tuvo lugar durante el huarachicuy. Ahí padre e hijo jugaron a los ayllos. El muchachito ganó cinco pueblos de Urcosuyu: Ñuñoa, Oruro, Asillo, Asángaro y Pucara, que por eso pasaron a llamarse aylluscas (Cobo [1653] 1968 II: 86-87); así, Topa Inca confirmó a su hijo en el gobierno de Urcosuyu (región antes bajo el mando del primer esposo de Guayro), lo apartó de las luchas por el curacazco de dichos pueblos y conservó la línea de sucesión.

En ambos casos, mediante un juego, el Inca pudo conseguir lo que pretendía; es decir, el resultado mostraba en parte la voluntad de una divinidad andina, y en otra los acuerdos previos entre los contendientes para alcanzar una solución pacífica a algún asunto dejándolo librado a la aparente decisión de dicha divinidad y la habilidad de los contendientes; los dos casos estuvieron relacionados con una aclla guayro, que no sabemos si fue siempre la misma persona, o si el Inca solía rodearse de esa clase de mujeres, cada una de las cuales había sido protagonista de un relato que los cronistas recopilaron sin discernir ese detalle, tal vez para no insistir sobre la poligamia incaica fuera del contexto asignado a dicha discusión.

\section{Las aclla Pomaguarme}

Del otro juego citado por Cobo, puma, solamente se conocía su nombre. Nuestra hipótesis acerca de su forma se basa en parte de los datos de una visita temprana al valle bajo de Cochabamba, en cuyas cercanías parece que también hubo un acllahuasi. En este padrón de Tiquipaya había cuatro mujeres apellidadas Guayro y otras tantas Pomaguarme (Gordillo \& del Río 1993: 79, 209, 217, 220, 226; 126, 163, 164, 262), es decir, sus nombres indígenas prehispánicos siguen ignotos. Sobre las guayro ya vimos que podían ser las acllas más bonitas y mejor instruídas, dadas en matrimonio por acuerdo político y con alguna incidencia en el desarrollo de un juego de tablero. Veamos si con las pomaguarme podría haberse dado una situación similar.

Respecto del nombre, el mismo no se refiere a la hembra del puma porque según diccionarios de época se decía china puma (Gonçalez Holguin [1608] 1952: 563) o cachu puma (Bertonio [1612] 1872: 275); tampoco una mujer esposa de un puma (Gentile 2007). 
Por otra parte, ya vimos que la voz Pumani significaba, además de jugar al juego de puma, la acción de cazar y matar las fieras a otros animales (Gonçalez Holguin, [1608] 1952: 294-295); notemos que fiera $=$ felino $=$ puma, y que este autor recopiló su diccionario mayormente entre quechuahablantes de la sierra y puna donde el puma es el felino mayor; en las tierras bajas era, $y$ es, el yaguareté.

En otras palabras, el juego de puma podría haber consistido en una cacería recreada sobre un tablero ya que en esta clase de juego, en general, las fichas se persiguen entre ellas. Una referencia etnográfica sería el juego "yagua" o "el tigre y los perros”, cuya área de dispersión no se conoce totalmente. Consiste en lo siguiente: un jugador enfrenta con una ficha-tigre a otro jugador que tiene diez a doce fichas-perro; la fichatigre se salva de quedar acorralada si consigue matar a más de tres perros, yendo y viniendo, tigre y perros, por los senderos marcados en el tablero, que son cuatro cuadrados yuxtapuestos dos a dos, con sus respectivas diagonales. Los avances por el tablero no se hacen de acuerdo con los tantos marcados con un dado sino que depende de la habilidad del jugador prever las consecuencias de sus movimientos y de los del contrario; en ese sentido, la lejana comparación con ajedrez sería correcta.

Hay un reporte para el Chaco, a fines del siglo XX (Magrassi \& Rocca ms) ${ }^{8}$, y en 1982 nosotros relevamos un tablero grabado por visitantes ocasionales sobre una mesa de madera dentro de la iglesia de Tafna (puna de Jujuy). Un tablero similar se encontraba grabado en un escalón del atrio de la iglesia de Chincheros (Alcina Franch, 1977: fig.3); lamentablemente, durante su larga estadía el autor no preguntó a los habitantes del pueblo (quienes se reunían a jugar en los varios tableros grabados en escalones y otras piedras

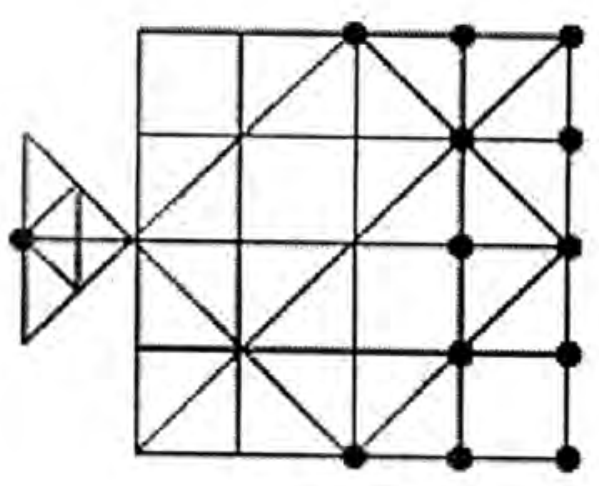

Figura 2. Tablero para jugar "yagua" o "el tigre y los perros", según Magrassi $\mathcal{E}$ Rocca, sin fecha. A esta versión publicada en la red global le falta una diagonal. Sin ella el juego es prácticamente imposible.

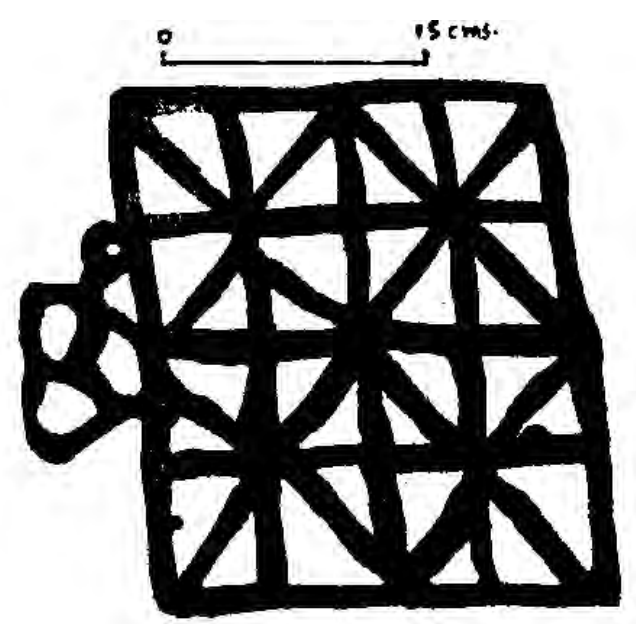

Figura 3. Tablero para jugar taptana grabado en las piedras de la entrada a la iglesia de Chincheros, Cusco, según Alcina Franch, 1977: figura 3 a. Es similar al yagua, y en los años 70' era funcional.

vecinas), acerca del dibujo y, siguiendo a Holm, lo denominó taptana porque un tablero similar estaba dibujado junto a Atahualpa (Guamán Poma, [1613] 1987: f.387); agregaba el cronista

Yagua, apócope de yaguareté (Pantera onça palustris).

8 En el dibujo publicado en el sitio de la red global falta una diagonal. 


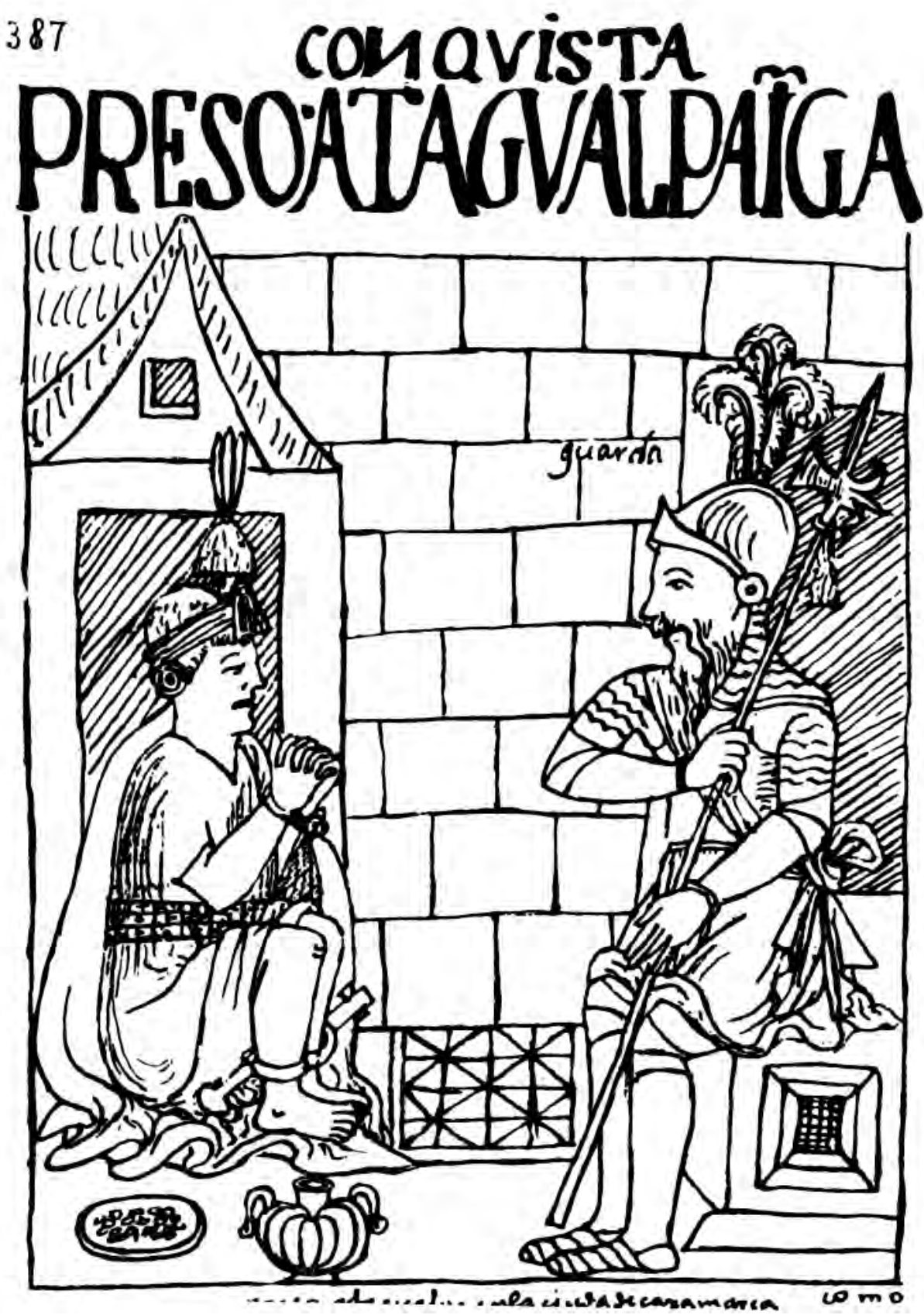

Figura 2. Atahualpa en prisión donde jugaba con los españoles "el juego de axedrés que ellos [los incas] llaman taptana.", según Guamán Poma, f.387. El tablero sería el dibujo que se ve entre el Inca y su guarda, similar al yagua jugado en el siglo $X X$. 
que el Inca "... jugaua con ellos en el juego de axedrés que ellos les llaman taptana.”, pero que según Cobo era tacanaco.

Recapitulando, tacanaco, taptana y puma prehispánicos se habrían jugado sobre un tablero similar al de yagua en el siglo XX; en caso de usarse un dado para obtener los tantos para avanzar, éste tendría la forma de la pirámide cuadrilátera trunca (pichca).

Con relación al significado y valor de las fichas, tanto tigre como puma son grandes felinos, de manera que el nombre de esa ficha podría considerarse entre las variantes regionales del juego. Varias fichas tratando de cazar a una, además, sugieren que el juego podría transcurrir en un ambiente similar al del relato de la madre de los mellizos Sol y Luna, perseguida por los tigres hambrientos (Sempé \& Gentile 2004, 2006; Gentile 2007). Es decir, en el juego prehispánico las fichas-perro habrían sido fichas-yaguareté, y la ficha-tigre habría sido una mujer.

Proponemos, entonces, que puma habría sido un juego que recordaba un relato básico en la visión del mundo andino; por esa razón no era de los juegos principales ${ }^{9}$, sino que su finalidad fue didáctica $^{10}$; y las pumaguarme fueron acllas relacionadas de alguna manera con el desarrollo y resultado de este juego.

En cuanto a las características físicas de estas mujeres, Gonçalez Holguín decía "Huacca, o puma runa. Quando tiene seis dedos en manos y pies como león." ([1608] 1952: 165), dato sugerente pero que sólo podemos citar porque, hasta donde sabemos, la polidactilia entre los andinos no pasó de poquísimos relatos circunstanciales y anecdóticos. En caso de haber sido estos dedos supernumerarios la razón de una categoría incaica, durante el gobierno español habría pasado a ser un "apellido" sin relación directa con el aspecto físico.

Quedaría todavía otra posibilidad por explorar: que las personas con dedos supernumerarios fuesen consideradas como portadores de dos naturalezas, humana y felina, que se manifestaba a voluntad; además, varios relatos acerca de los felinos nacidos de mujer avalarían estas creencias a lo largo del piedemonte andino (Gentile, 2007). Su asociación con el juego citado tal vez se diera en un ambiente tan restringido como el de la consulta a un oráculo. ${ }^{11}$

\section{Las aclla Hochaguarme}

En los diccionarios del siglo XVI y principios del XVII, ocha / hucha formaban parte de voces que definían, o daban idea, de trato o asunto establecido sobre el que ya no cabía ninguna discusión; pero también se relacionaba complejamente con los pecados y, sobre todo, con los no confesados; de ahí que "capacocha" fue interpretada como "pecado del soberano" (Duviols, 1976: 41) o "afrenta del inca" (Urioste en Guamán Poma [1613] 1980: 221) por ejemplo, sin tomar en cuenta las descripciones que de estas ofrendas habían hecho los cronistas.

En la visita a Tiquipaya hay un grupo de mujeres Hochaguarme. Nos preguntamos si

\footnotetext{
9 Sus resultados cambiaban el estado actual del entorno o mundo conocido.

${ }^{10}$ Repetir el relato, trasladando esa repetición hacia el futuro para conservar la creencia.

${ }^{11}$ Sobre este tema, la persona que leyó mi trabajo para esta Revista decía: "En Cajamarca, en el norte peruano, a los niños nacidos con seis dedos se les sigue considerando hijos del rayo o de Catequil, una importante deidad-oráculo andina, que en ceramios de la tradición Cajamarca es representado también con seis dedos. En el relato registrado por los padres agustinos, Catequil tiene un mellizo Piquerao, ambos se enfrentan a los Guachemines que habían dado muerte a su padre y perseguido a su madre. En este contexto, la propuesta de la autora [MEGL] que Pomaguarme fueron acllas relacionadas al juego del puma, adquiriría mayor solidez.”. Compromete mi agradecimiento por el dato actual que, a su vez, refuerza lo que propuse sobre la madre de todos los tigres, trabajo en evaluación cuando presenté éste.
} 
acaso estuvieron relacionadas con capacocha y, por ende, con acuerdos políticos. En lo que sigue veremos ese punto.

En Yucay se reunieron seis grupos de testigos indígenas a quienes se les preguntó, por orden del virrey Toledo, acerca de los aspectos religiosos de las costumbres de los Incas (Levillier [1571] 1921-1926 II). No se usó la voz capacocha en este texto pero en el mismo hay puntos en los que los testigos coincidieron, y aunque afirmaron que todos los Incas tuvieron esta costumbre, recordaron con precisión a Topa Ynga y Guayna Capac.

Según ellos, todas las provincias enviaban niños al Cusco, y allí eran seleccionados estrictamente en base a que no tuvieran ni manchas en la piel y ni lunares. En un caso se afirmó que esta ceremonia se hacía tres veces por año y en otro único caso que

"... el origen que tuvo esta orden de sacrificio, fué que cuando los Ingas comenzaron a conquistar esta tierra, vieron que los indios de la Provincia del Collao hacían el dicho sacrificio de los dichos niños a sus dioses, y entendieron que por esta causa no los podían vencer y por esto los dichos Ingas comenzaron a hacer y hicieron los dichos sacrificios y los vencieron, y después de esto se había tomado costumbre de lo hacer, y que así se lo dijeron sus antepasados y esto saben de esta pregunta." (Levillier [1571] 19351942 II: 170).

Esto coincide con los hallazgos de capacochas en el Collasuyu, región explorada por Pachacuti, conquistada por Topa Inca Yupanqui y organizada por Guayna Capac. En nuestra opinión, el tema se relacionaba con pactos políticos, ya que para ofrecer estos niños había que tener a quien pedírselos y, a su vez, dar algo a cambio. Mientras el Cusco fue uno de tantos curacazgos, la red de reciprocidades debió ser tenue y limitada; recién después de Pachacutec se podría haber implementado esta clase de compromiso anclado en las creencias sur-andinas, las que versaban sobre temas como que la persona ofrecida en capacocha quedaba convertida en una huaca y era capaz de dar oráculos. ${ }^{12}$

En cuanto a la "limpieza" de los niños, sobre la que insistieron todos los testigos en Yucay, la misma podría entenderse en términos europeos como una metáfora de pureza e inocencia, pero en el contexto que estamos viendo la falta de manchas en la piel, cualquiera sea su origen, podría remitir a que entre los ancestros del niño no había tigres. ¿Acaso los tigres y sus descendientes humanos estaban intedictos, por aquello de que un Inca y su hijo habían tenido esa peculiaridad? ¿Se temía provocar la ira de sus descendientes quienes, aunque antis, eran aliados del Cusco?

La exigencia de una piel sin manchas debe de haber sido difícil de cumplir, de ahí que no nos resulta del todo creíble que hayan sido tan numerosos los "sacrificios humanos" como dicen los cronistas; además, los hallazgos de esta clase de ofrendas tampoco corresponden numéricamente con las crónicas. Lo que las crónicas parecen más dispuestas a contabilizar es la cantidad de niños llevados al Cusco para ser inspeccionados $y$, eventualmente seleccionados, pero no los que regresaron rechazados por sus imperfecciones, y tampoco dicen si, superado el número deseado para determinada ofrenda, los restantes perfectos no pasaran a formar parte de un grupo selecto de cuya reproducción se esperara lograr niños sin manchas en la piel. Esta pregunta surge de la lectura de la visita realizada a Tiquipaya en 1573, en la que llama la atención los apellidos que incluyen el morfo "ocha": Hochama, Hochani, Hachatoma, Hochacara, Hochaguampa. De 61 personas, ocho eran varones y, de entre las mujeres, once se llamaban Hochaguarme. En cuanto

\footnotetext{
${ }^{12}$ También las huacas locales, que los incas llevaban con honores al Coricancha, daban oráculos, sobre todo relacionados con la fidelidad de sus pueblos de origen al Inca.
} 
a los hombres y su rol con relación a este tipo de ofrendas, tenemos que trece niños entre un mes y doce años tenían alguno de dichos "apellidos".

También, desde un mes hasta 65 años, todos los grupos de edad estaban bien representados; y el segunda persona del ayllu Collana era Don Phelipe Hochacara, cuya hija de dos meses de edad se llamaba María Hochama.

Las preguntas que, a nuestro entender, quedarían por responder a partir de más y mejor documentados estudios serían, por ejemplo, si estas personas formaron parte de una categoría social relacionada con los sacrificios ofrecidos durante el Tahuantinsuyu que, por ser tan temprana la visita, habían sumado a sus nombres de pila aquellos rótulos incaicos.

Por lo que venimos de ver acerca del ámbito de las acllas, las once Hochaguarme permiten preguntarnos si acaso también hubo algún juego de tablero relacionado con ellas, y con qué fin.

Llegamos hasta aquí sin citar a Tanta Carhua, tal vez la capacocha más conocida antes que la Arqueología confirmara en parte a los cronistas. Es probable que ese nombre fuese el último cambio en su vida; y sería, hasta donde sabemos, la única capacocha realizada fuera del Collasuyu, de manera que las interrogantes que abre son muchas más que las preguntas que su presencia podría contestar. Veamos esto.

Tal vez el Tahuantinsuyu, a partir de Topa Inca y en su búsqueda de optimizar recursos, ${ }^{13}$ reservó gente sin manchas ni defectos para reproducirla en función de las capacocha. Con esto se evitaba el traslado hacia las llacta, luego el viaje al Cusco, la estadía en la ciudad y el regreso a los pueblos; en otras palabras, se evitaba la concentración de gente en alguna parte, y la suspicacia de rebelión. Esta gente reservada, viviendo aparte del resto, eran los "ocha", hombres y mujeres.

En el caso de Tanta Carhua, su nombre no tiene que ver con los nombres que venimos viendo, de dónde se podría decir, con un margen de verosimilitud, que su nombre previo terminaba en "ocha". Si hubiese sido así, fue una capacocha correspondiente al Tahuantinsuyu. Pero si no fue así, podría haber sido anterior, o colonial o, más simplemente, no ser una capacocha.

Notemos que los confidentes de Hernández Príncipe le presentaron ese entierro como un hito o mojón que delimitaba terrenos. Dado que el relato transcurría cuando ese tipo de hallazgos ya eran raros, se puede suponer casi con seguridad que de lo que se trataba era de validar los límites de esos terrenos haciendo referencia a derechos adquiridos "del tiempo de los Incas". Notemos que, por la misma fecha Arriaga proponía que si el huanca era el dueño de las chacras donde estaba, entonces dichas chacras debían pasar a propiedad de la Iglesia como otrora las chacras del Sol (Arriaga, [1621] 1968: 204; Gentile, 2007ms). En otras palabras, si traemos aquí a Tanta Carhua, lo hacemos con las reservas señaladas.

Las consecuencias de esta propuestas afectan directamente a las afirmaciones que dicen que la capacocha eran hijos de curacas y que se hacían exclusivamente por pacto político. Aquí hay que discernir entre los gobiernos de Pachacutec, Topa Inca y Huayna Capac. Con el primero la capacocha fue una ofrenda política, de intercambio. Tal vez algún hijo/a de curaca mereciera ser reservado por su belleza, pero si como parece- había grupos de gente reservada desde tiempo de Topa Inca, entonces este inca

\footnotetext{
${ }^{13}$ Parece que fue Topa Inca quien "inventó" los yanaconas, gente que no respondía a la reciprocidad y el intercambio al estilo estrictamente andino sino solamente de las órdenes del Inca o la Coya; esta condición parece que era hereditaria. Esto restringió la manufactura de los elaborados regalos que se daban a los curacas cada vez que se los reunía para "rogar" una mita, y la movilización consiguiente de gente para reunirse con ese fin, por ejemplo.
} 


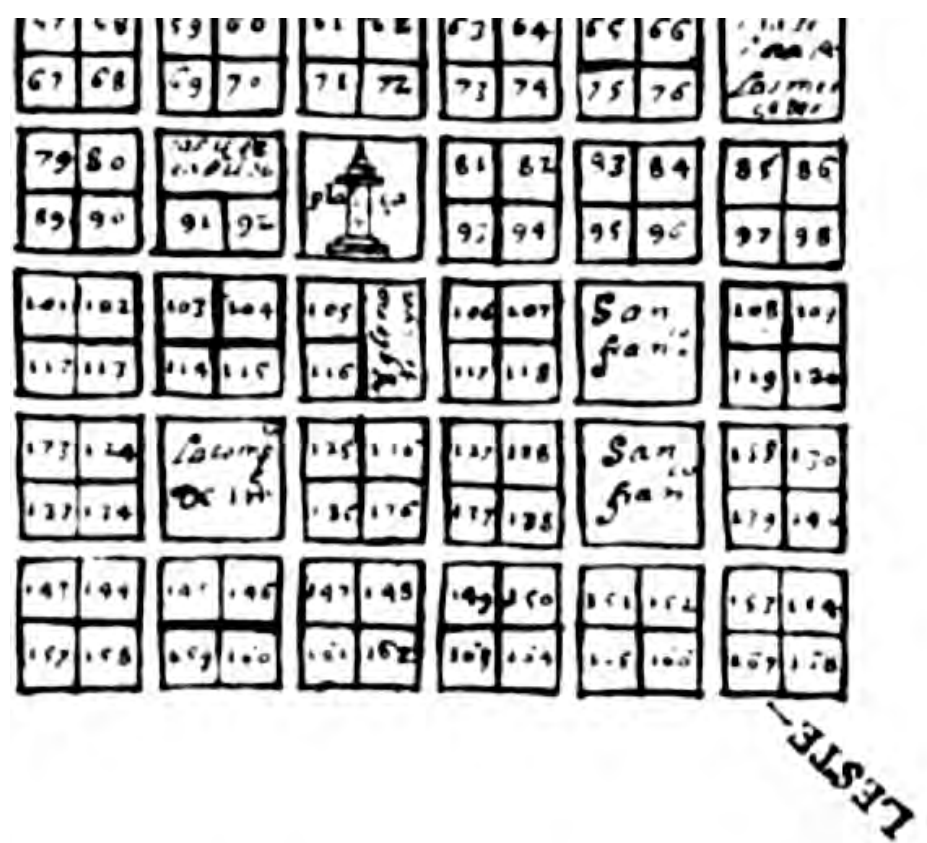

Figura 5. Detalle del primer plano de la ciudad de Esteco (1610) donde se ve el solar número 92, que corresponde a Doña Tomasina; en la lista, más abajo, se indica que tiene 80 indios. Según Torre Revello, 1943: lámina 3.

testamento que era hija natural de Gonzalo de Morales y de Ysauel Paya, difuntos antes de esa fecha, y viuda de Alonso Martín del Arroyo.

Ysauel Paya habría sido una mujer del linaje del Inca que él solía dar a los curacas como prenda de parentesco político $^{15}$, de donde su esposo habría sido un curaca yanaco-

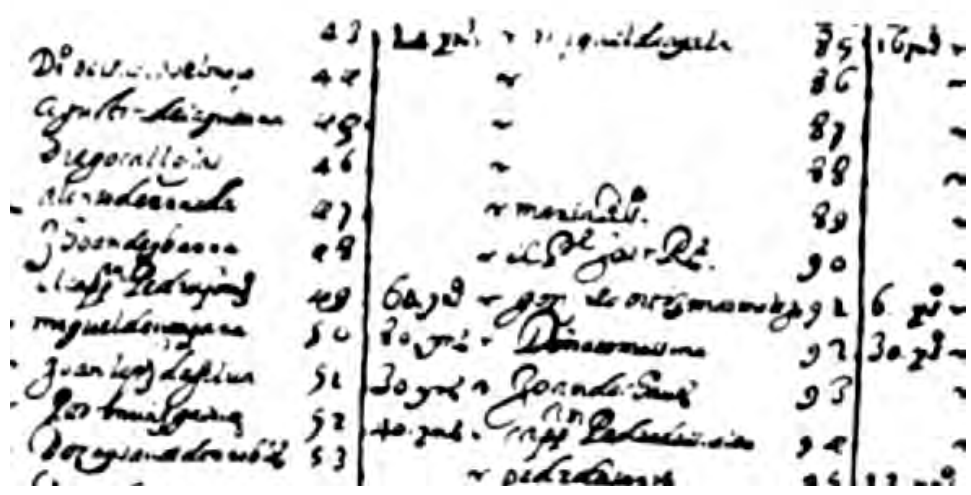

logró quebrar otra de las reglas de la reciprocidad andina al sacar la capacocha del ámbito políticoreligioso; al disponer de gente reservada para esto, era el inca quien actuaba sin mediación y establecía la oportunidad y características de la ofrenda máxima del Tahuantinsuyu.

Ysauel Paya (c.1570), y doña Catalina

En 1609, en la ciudad de San Miguel de Tucumán ${ }^{14}$, Doña Catalina de Morales dijo en su na, o aliado fiel del Inca, ya que en el entorno geográfico hubo asentamientos de mitmacuna; en cuanto a Alonso, había sido - procurador de San Miguel (Levillier, 1928 II: 25, 273, Lizondo Borda, 1936 I: 30, 41, 50; Gentile, 1998).

Doña Catalina tenía en su casa nueve indias e indios de servicio, además de gran cantidad de vajilla de plata; dejó a sus indios una importante cantidad de ganado y mandó que se dijesen misas por los del pueblo de Marapa "que me han seruido". Otra manda señalaba que tenía límite en los días de su vida la merced de una pensión de 150 pesos anuales que el gobernador Pedro de Mercado y Peñalosa, (1594-1600), le habia hecho a su madre, Ysauel Paya, sobre el pueblo de Marapa, pagados por su encomendero.

\footnotetext{
${ }^{14}$ Fundada en 1565 en Ibatín, al pie del nevado Anconquija (Levillier, 1928 III: 232-233).

${ }^{15}$ Estas mujeres eran portadoras de la cultura que el Cusco quería establecer como característica del Tahuantinsuyu entre las elites aliadas.
} 
Esta merced - en realidad, un salario - a una india indicaba que ella tenía autoridad sobre una población indígena; Marapa era frontera con el valle donde Juan Calchaquí había liderado una rebelión alrededor de 1560, latente en tiempos del gobernador Mercado, de ahí la importancia de una alianza con la curaca regional y su salario tan alto. En comparación, la tasa de Toledo mostraba salarios que no llegaban a ochenta pesos; también parecía haber una relación entre la cantidad de indígenas a cargo del curaca y su salario; en promedio, el salario eran unos 63 pesos por cada 8979 indios (sin distinción de sexo ni edad). Si Ysauel Paya y su hija Doña Catalina cobraron 150 pesos por año, el cacicazgo de Marapa habría tenido unas 21.378 personas. ¿Cuántas personas había en "tambo del ynga" que estaba en el piedemonte tucumano, al pie del santuario incaico del nevado Anconquija? (Matienzo, 1966: 281; Hyslop \& Schobinger, 1990) iy cuántas otras en poblaciones de mitmacuna? (Gentile, 1998).

Figura 6. Detalle del segundo plano de la ciudad de Esteco, realizado el mismo año y en el que se corrigieron la ubicación de solares y cantidad de indios encomendados a sus vecinos sin modificar los correspondientes a

Doña Tomasina. Según Torre

Doña Tomasina (c.1600)

La ciudad de Cáceres fue fundada en 1566 en la "provincia de Esteco", a unas 45 leguas al norte de Santiago del Estero ${ }^{16}$; el sitio estaba dentro de la gobernación de Tucumán, a orillas del río Salado, entre montes de algarrobo y arenales donde no hubo fundación incaica previa.
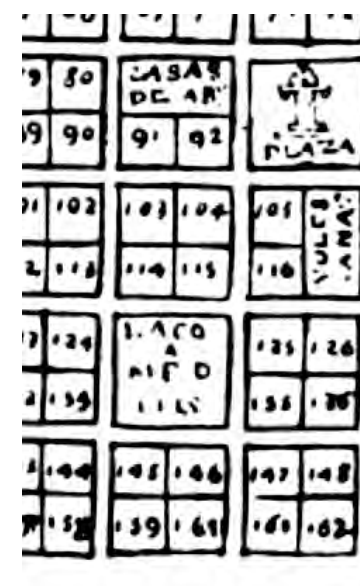
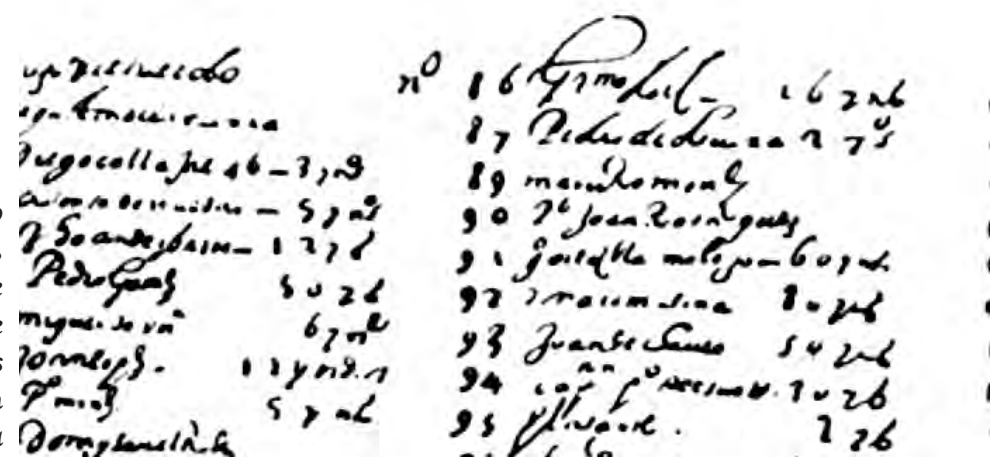

Revello, 1943: lámina 4.

\footnotetext{
${ }^{16}$ Santiago del Estero fue fundada en 1553 a orillas del río Dulce, por orden del gobernador Francisco de Aguirre; la región había sido un importante establecimiento incaico dedicado al cultivo e hilado de algodón.
} 
Cáceres no se estableció con las ceremonias usuales porque sus fundadores se habían sublevado contra el gobernador Francisco de Aguirre. En poco tiempo la rebelión fue deshecha, sus cabecillas ajusticiados y la Audiencia de Charcas aprobó esto sin objeciones. En 1567, el nuevo gobernador llamó a la fundación Nuestra Señora de Talavera y designó nuevos alcaldes porque la ciudad estaba poblada.

La vida de Talavera de Esteco transcurrió con altibajos de guerra y paz entre los mismos españoles; además de la iglesia principal, había un convento de franciscanos, otro de mercedarios y un hospital. Pero era una población fronteriza con los indios del Chaco, los temidos chiriguanos. En 1610 esta ciudad se unió a otra y ambas tomaron, en un nuevo sitio, el nombre de Nuestra Señora de Talavera de Madrid. Torre Revello publicó dos plantas de la nueva ciudad con un cuadro comparativo de los solares de cada vecino y el número de indios asignados (Torre Revello, 1943: láminas 3 y 4).

Nos interesa señalar aquí que en esta nueva fundación, de un total de 119 vecinos, quince eran mujeres. Todas, excepto Doña Tomasina, tenían apellido; la mayoría no tenía indios pero ella tenía ochenta, y un solar junto a las casas del cabildo, frente a la plaza. El resto de las mujeres tenían solares junto, o a una o dos cuadras de la ronda, detrás de la catedral o a dos cuadras de la plaza. Doña Felipa del Sueldo era la más cercana, en la esquina sudoeste de la plaza, pero no tenía indios. De los encomenderos, Francisco Mexía Miraval y Pedro Méndez de Herrera tenían 140 indios cada uno; la mayoría no tenía ninguno, y el resto tenían entre tres y ochenta indios, generalmente no más de veinte.

Por eso somos de la opinión que Doña Tomasina podría haber sido la heredera del cacicazgo de esta región fronteriza, y para mantener abierta la ruta entre Santiago del Estero y Potosí debe de haber sido necesario conservarle -o darle-prebendas y calidades.
La importancia de la fundación de 1610 menguó cuando las ciudades ubicadas sobre el antiguo camino incaico pudieron sostenerse; y decayó hasta entrar en la leyenda con la profecía adjudicada a San Francisco Solano, el malón de 1686 y el terremoto de 1692 .

Pero en 1610 Doña Tomasina (solar frente a la plaza, ochenta indios), era una mujer importante en el contexto de la nueva fundación, ilo era antes, con relación a alguna de las villas refundadas? Su falta de apellido permite suponer que era india, soltera y que había sido bautizada ipor un fraile dominico?. También puede haber sido la heredera de un cacicazgo según la normativa española, y que tuviera el cargo de su padre o esposo hasta volver a casarse, aunque dicho cargo no se agregara a su nombre.

Asimismo, era claro el intento español de mantener a los indígenas de la región bajo un mando para negociar con una única autoridad indígena regional.

Notemos, sin salirnos del tema, que la región fue siempre interesante. En 1575 los alrededores de Santiago del Estero "era tierra viciosa de cocas y de mucha gente" (Góngora Marmolejo, [1575] 1960: 96); en 1669, un soldado mercenario español que había participado en el último tramo de la guerra de Calchaquí decía que había descubierto coca en Esteco y proponía su cultivo y, por supuesto, su estanco. Entretanto, su premio fue una merced de tierras (Larrouy, 1923: 292). En el siglo XVIII, la hoja de coca que llegaba a las minas de Catamarca procedía del piedemonte tarijeño, y cien años después Martin de Moussy decía que había coca silvestre en Orán y San Francisco, hacia el noreste de Esteco (Moussy, 1860 (I): 495).

Volviendo a la rebelión de 1566 contra el gobernador Aguirre, tal vez la misma fue un golpe de mano para tratar de ganar tierras para cultivar coca y estancarla antes que el codicioso gobernador lo hiciera; pero si algunos pensaron así este negocio, lo hicieron sin considerar que 

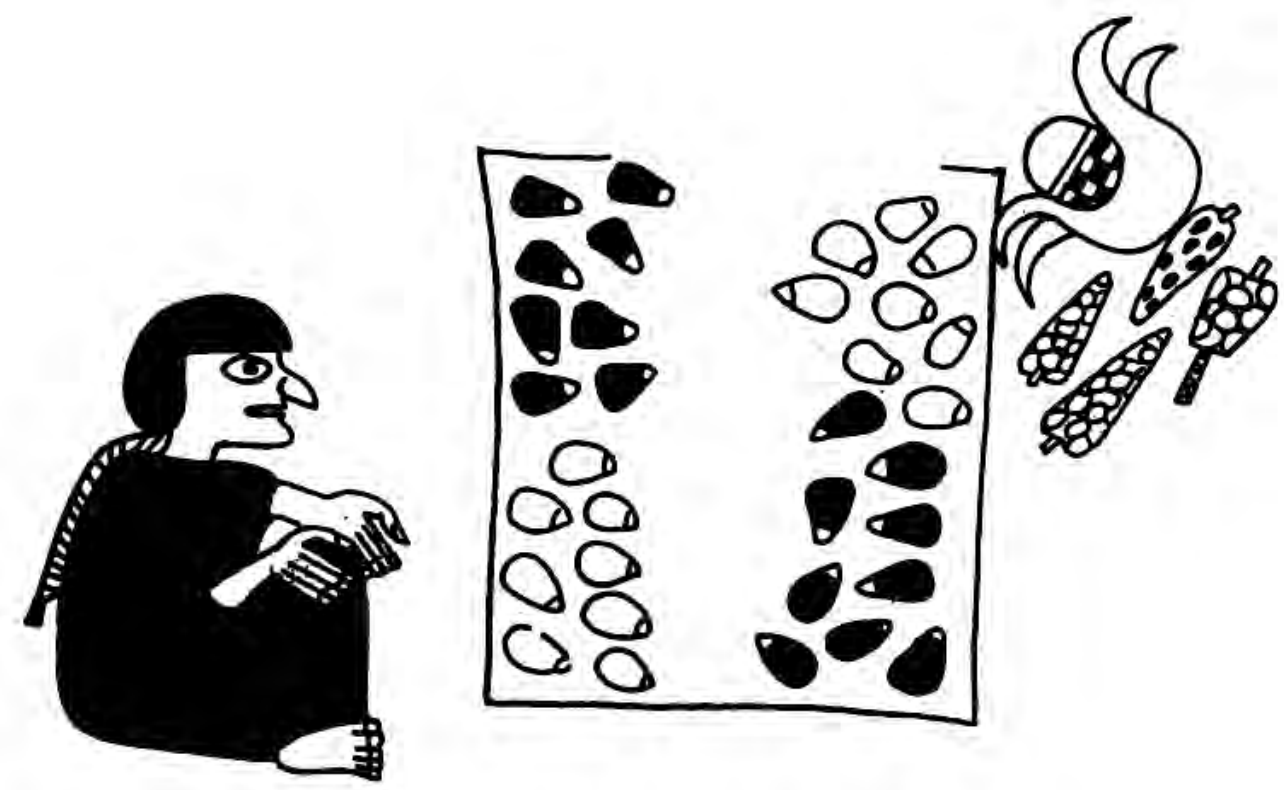

Figura 7. Dibujo sobre alfarería mochica donde se ve una mujer sentada frente a una manta con granos de maíz agrupados por colores (Según Hocquenghem, 1989: figura 162).

faltándoles el liderazgo de la mano de obra indígena su proceso no sería posible, tal como parece que sucedió. O, por lo menos, no en la medida esperada.

\section{Doña María Chalipi}

Fue la esposa del cacique quilme Francisco Pallamay, fallecido en la reducción de Santa Cruz, en la costa del río de La Plata, tras haber sido transterrados los quilmes y acalianos después de la guerra de Calchaquí, en 1665.

El nombre, Pallamay, indicaría en la lengua de los diaguitas que podía tratarse de un cacique local aliado de los cusqueños que había recibido una mujer del linaje del Inca como prenda de alianza (Gentile, 1997: 317) ${ }^{17}$. A su vez, Francisco era nieto de Martín Yquín, el curaca que había viajado con el remanente de sus indios desde el valle de Santa María (entre las actuales provincias argentinas de Catamarca y Tucumán) hasta ese territorio húmedo, sin montañas ni piedras; en su nuevo habitat, los quilme sembraron trigo, continuaron criando caballos, adorando al Rayo, y alguno navegaba hasta el puerto de Montevideo. El gobernador de Buenos Aires solamente les pedía que vigilaran la costa del Río de la Plata ante la posible presencia de corsarios.

El juicio por la sucesión en el cacicazgo de Francisco Pallamay fue largo y nadie la llamó a declarar en él; pero Augustín Filca fue investido

\footnotetext{
17 "Entre el número de antropónimos se halla el quilme Tancolmay. Pues bien, "tangol” se conoce como voz incorporada al quichua santiagueño con el significado de "arco para flechas" (no la conozco en ningún otro dialecto quechua). Es posible que "may" sea un sufijo de derivación (no aparece precediendo las construcciones); "tancolmay" podría ser algo así como "arquero"; también podría suceder que "may" fuera un calificador y la construcción significara "arco fuerte", "arco bravo", "arco certero", etc.." (Nardi, 1979: 29). Esto es hoy día difícil de comprobar por ser el cacán una lengua extinguida; no obstante nos permitimos notar que si Pallamay fuese un antropónimo cacán influenciado por el quechua, su traducción podría haber sido algo así como "mujer elegida y poderosa", o similar.
} 
por el gobernador español mediante la entrega del bastón que había sido de Francisco, insignia que guardaba María Chalipi con orden de su esposo de entregarla a Augustín "cuando fuese de edad suficiente para mandar" (Gentile, 1997).

A partir de 1704 la hija de Francisco y María, Ysauel Pallamay, pretendió y ganó el cargo, gobernando su marido conforme a la normativa española. En 1708 María Chalipi aún vivía, pero su influencia continuó siendo tan discreta como la de Diego de Santiago, encargado de las ofrendas al Rayo en la reducción de Santa Cruz de los Quilmes.

En los padrones de 1716 y 1717 figuraba entre las viudas quilme Doña María Chaupi; en el de 1718, año de la peste, ya no estaba. El "Doña" nos permitió suponer que se trataba de Doña María Chalpi o Chalipi. Por otra parte, la voz quechua chaupi indica "mitad, o el medio de cosas o lugares o tiempo, o obra" (Gonçalez Holguin, [1608] 1952: 99). En el contexto del pleito por la sucesión del cacicazgo, el rol medidador de esta mujer fue claro y su nombre indígena lo estaba diciendo; ipodría tratarse de una grafía errada en los documentos más tempranos? io podría ser un caso de cambio de nombre como consecuencia de un suceso histórico importante para el grupo?

\section{Consideraciones finales}

En este ensayo nos propusimos aproximarnos al quehacer de mujeres andinas de las cuales se tienen menos noticias que de las que formaron parte de las elites del Tahuantinsuyu; éstas por sus parentescos con Incas y españoles, fueron centro de documentación a veces tan detallada como pueden serlo los testamentos y pleitos.

Hemos visto que los nombres con que se las conoció, en el caso de las aclla, no eran tanto nombres propios sino que se las identificó con la categoría que detentaban al interior del grupo de mujeres elegidas que, tras el bautizo, pasaban a ser apellidos; de esta manera se amplía el número y nombre de las categorías conocidas.

Queda pendiente el estudio que había propuesto John V. Murra (1972: 432, nota 8), de los nombres de las mujeres en las visitas tempranas.

Por otra parte, si la trascripción de la visita a Tiquipaya es correcta, en ella tenemos mujeres cuyos "apellidos" merecen más atención: Ansaguarme, Hansaguarme, Panpaguarme (imujer común?), Cochaguarme (imujer arrugada, vieja?), Copaguarme, Charcoguarme, Sulcaguarme (¿la menor?) y Consaguarme. Y si fueron acllas sus nombres aumentarían el número de categorías conocidas, también.

Es interesante, y el tema no parece agotado, la presencia de mujeres en ambientes lúdicos y, a su vez, la resolución de temas políticos mediante oráculos / juegos, con más o menos incidencia de la habilitad de los participantes en su desarrollo.

Un antecedente preincaico lo tenemos en una vasija Moche en la que se ve a una mujer ${ }^{18}$ de perfil, sentada en el suelo con las piernas cruzadas frente a un paño tendido ${ }^{19}$ sobre el que hay dos tipos de granos de maíz, claros y oscuros, separados por color, formando cuatro grupos, tres de ellos con número par de granos y el restante, impar. Las mazorcas ${ }^{20}$ están junto al paño, una de ellas muy estilizada. En opinión de Hocquenghem ésta sería una de las "escenas de juego" que formaban parte de un momento del calendario andino; para probarlo repasó crónicas y trabajos acerca de juegos, y aunque publicó la imagen (figura 162), no se refirió a la misma en el texto (Hocquenghem1989: 147). Sin embargo, Arriaga describió una escena que debe de haber

\footnotetext{
${ }^{18}$ Por la trenza que le cae sobre la espalda.

${ }^{19}$ La escena fue dibujada según dos perspectivas: de perfil en la mujer, rebatida en el paño y las mazorcas.

20 Se trata del llamado maíz overo en el área andina argentina.
} 


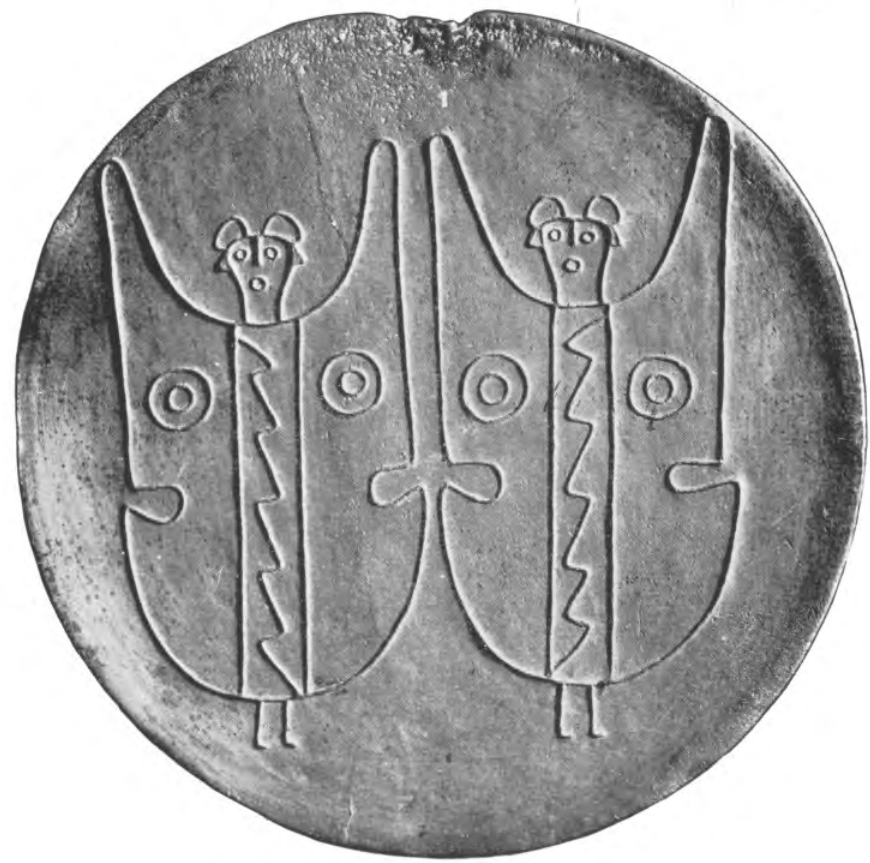

Figura 8. Disco de metal con figuras en relieve que representan dos personas tras escudos; tanto los senos como la banda vertical en zig-zag relacionan al dibujo con mujeres itras los escudos?. Publicado por González, 1977: fig.319. Diámetro $27 \mathrm{~cm}$.; espesor 5 mm. Procedencia: Cerro Negro, Catamarca. Cultura Belén.

sido muy parecida, aunque protagonizada por un hombre:

"De los ministros de las idolatrías. ... Socyac es sortílego y adivino por maíces; hace algunos montoncitos pequeños de granos de maíz sin contallo, y después va quitando uno de una parte y otro de otra, y conforme quedan pares o nones, es buena o mala la suerte. Aunque en un pueblo exhibió uno de este oficio una bolsa con muchas piedrezuelas que dijo se llamaban chunpirun y que las había heredado de su abuelo para este efecto." (Arriaga [1621] 1968: 206).

También se usaba el maíz para adivinar en Concepción de Chupas (Duviols, 1966: 506) y en Tupe, Yauyos (Frisancho 1973: 53), entre otros autores.
Aquí nos interesa puntualmente que en Moche era una mujer quien se sentaba, aparentemente sola, frente a un espacio diferenciado y delimitado por los bordes de la tela, que es también un "tablero" donde podían transcurrir el oráculo y el juego. Ya en trabajos previos hicimos notar cómo algunos rasgos de las culturas Moche y Chimú fueron incorporados por los cusqueños al Tahuantinsuyu; por su parte, A.R. González había señalado hace años la similaridad de rasgos culturales entre regiones andinas alejadas (González, [1971] 1978).

Por lo que venimos de ver, las mujeres Guayro fueron parte de los oráculos que, durante la época incaica, habían tomado la forma de juegos con amplio margen para la exposición de la

\footnotetext{
${ }^{21}$ Aunque probablemente en todas las épocas los gobernantes andinos deben de haber tratado de obtener de los oráculos las respuestas más convenientes, a riesgo del oráculo mismo de ser destruído.
} 
habilidad del jugador (incluso para hacerse perdedor, como Topa Inca frente a su hijo jugando ayllos). El carácter de oráculo o juego estaba dado por los participantes, es decir, entre gente común no pasará de ser un mero pasatiempo aunque mediaran apuestas y se conservara un componente oracular sin trascendencia política.

También las Pomaguarme podrían haber estado relacionadas con un juego de tablero, pero en ese caso no sería el Inca uno de los jugadores porque puma se encontraba entre los juegos menos "principales".

En cuanto a las Hochaguarme, si estuvieron relacionadas con las ofrendas máximas del Tahuantinsuyu, podemos ubicarlas cronológicamente como grupo a partir de Topa Inca Yupanqui y la conquista efectiva del Collasuyu; además, la persistencia de los nombres de niños y niñas en 1573 sugiere que podría haber habido capacochas más tardías de lo que hoy se admite o, también, que los andinos vivían el momento como una espera de regreso a las costumbres prehispánicas para las que no querían estar desprevenidos.

Los cusqueños implementaron una estrategia de expansión del Tahuantinsuyu que incluía su intervención directa en la formación de los oráculos a partir de otra manera de consulta a los mismos con el propósito de interferir el poder de las divinidades andinas preincaicas. Un ejemplo de esta manipulación la encontramos en el relato de la aparición de Llocllayhuancu en Huarochirí; la mujer que encontró a este hijo de Pachacamac lo mostró a sus parientes; éstos lo presentaron en el pueblo de Llacsatampu a un huaca llamado Catiquilla, el cual había sido enviado por el Inca, y que “... tenía el poder de hacer hablar a cualquier otro huaca aunque él no quisiera o no pudiera hablar." (Ávila [1598?] 1966: cap. 20; también Ávila en Taylor 1987: 293). Los relatos de Huarochirí abarcaron sucesos producidos durante los gobiernos de
Pachacutec y Topa Inca, de manera que el cambio en la forma de consulta de un oráculo y, sobre todo, la determinación de cuáles huacas regionales podían ser oraculares, podría ubicarse, también, en el marco de esta cronología relativa. ${ }^{21}$

Durante la colonia la perspectiva cambió en el sentido de que el quehacer femenino quedó encuadrado en la normativa europea que limitaba su influencia al interior de su grupo familiar, y la mujer siguió siendo una prenda, una intermediaria.

En el área andina argentina, aún no sabemos si hubo aclla huaci; aunque tendría que haber habido uno, dada la cercanía del Cusco fundado en Nasauacollo por Pachacutec en homenaje a su hijo muerto en la conquista de la región de los chichas (Gentile, 1991-1992). Probablemente este sitio fue Maquijata, en la sierra de Santiago del Estero, donde se encontraron miles de muyunas y, además, estaba cerca de las plantaciones de algodón del río Dulce, pero el sitio fue desestimado como incaico porque no se ubicó el capac ñan. Por otra parte, el topónimo Maquijata es por demás expresivo. Otro sitio adecuado hubiese sido el piedemonte del nevado Anconquija, donde Matienzo ubicaba un "tambo del inca", pero la zona fue puesta bajo cultivo intensivo de caña de azúcar en el siglo XIX y en los últimos treinta años los deshielos arrasaron áreas significativas.

Aquí los nombres de pila se impusieron rápidamente, antes de fines del siglo XVI; la herencia de los cargos de curaca se hizo en la dirección de sus viudas e hijas, las cuales eran dadas en matrimonio a españoles a fin de direccionar la línea sucesoria hacia fuera de los grupos indígenas mediante sucesivos matrimonios de mestizas con españoles. En los casos que venimos de ver, esta situación es notable a pesar de la austeridad de los textos pero, además, el análisis de los patrimonios señaló articulaciones en los cambios como consecuencia de la situación de conquista 
y colonización europeas, al mismo tiempo que, de tanto en tanto, emergían algunas continuidades en la documentación tardía. En ese sentido, notemos para finalizar, que tanto apaytalla como puma tienen registro etnográfico en Chaco, igual que los quero de madera sin grabar, la costumbre de deformarse el lóbulo de la oreja, chacchar hoja de coca, cultivar maíz y preparar chicha, entre otros rasgos distribuídos entre los grupos de la región pero con mayor presencia entre los maká hasta mediados del siglo XX. A partir de esto, volvemos a preguntarnos si al piedemonte sudeste del Collasuyu, ¿huyeron? ¿o estaban allí y la documentación de época no los registró?, los funcionarios / partidarios ide Atahualpa? ide Huáscar?, durante las matanzas entre panacas para heredar a Huayna Capac, incrementadas dichas masacres por el desembarco de Pizarro y la embestida española en Cajamarca. Sería interesante para la historia andina nuevas indagaciones sobre estos temas, que de esa manera saldrían de las generalizaciones y se conocerían con puntualidad.

\section{Bibliografía}

Alberti Manzanares, Pilar

1986 "Una institución exclusivamente femenina en la época incaica: las acllacuna”. Revista Española de Antropología Americana XVI: 153-190. Universidad Complutense, Madrid.

Alcina Franch, José

1977 "Juegos y ritual funerario en Chincheros (Cuzco)". Actas del III Congreso Peruano del Hombre y la Cultura Andina, tomo IV: 441-456. Universidad Nacional Mayor de San Marcos, Lima.

Anónimo (iAlonso de Barzana?)

[1586]1951 Vocabulario y phrasis en la lengua general de los indios del Perú llamada qui- chua y en la lengua española; Universidad Nacional Mayor de San Marcos, Lima.

Arriaga, Pablo J. De

[1621] 1968 La extirpación de la idolatría en el Perú. In: Biblioteca de Autores Españoles CCIX: 191-177. Ediciones Atlas, Madrid.

Avila, Francisco de

[1598?] 1966 Dioses y hombres de Huarochirí. Museo Nacional de Historia - Instituto de Estudios Peruanos, Lima.

Avila, Francisco de, en: Gerald Taylor

1987 Ritos y tradiciones de Huarochirí del siglo XVII. Instituto de Estudios Peruanos IFEA, Lima.

Bertonio, Ludovico

[1612] 1879 Vocabulario de la lengua aymara compuesta por el padre... Julio Platzman, Leipzig.

Betanzos, Juan Díez de

[1551] 1987 Suma y narración de los Incas. Ediciones Atlas, Madrid.

Cieza de León, Pedro

[1553] 1967 El señorío de los Incas. Instituto de Estudios Peruanos, Lima.

Cobo, Bernabé

[1653] 1964 Historia del Nuevo Mundo. In: Biblioteca de Autores Españoles, 2 tomos. Ediciones Atlas, Madrid.

Donnan, Christopher B. \& McClelland, Donna

1999 Moche fineline painting. Its evolution and its artists. UCLA Fowler Museum of Cultural History, Los Angeles.

Duviols, Pierre

1966 La visite de idolâtries de Concepción de Chupas. Journal de la Société des Américanistes LV-2.

1976 La Capacocha, mecanismo y función del sacrificio humano, su proyección geométrica, su papel en la política integracionista y en la economía redistributiva del Tawantinsuyu. Allpanchis IX: 11-57. Cusco. 
Ellefsen, B.

1982 Las concubinas de los Sapa Inca difuntos. Boletín del Instituto Francés de Estudios Andinos XI (1-2): 11-18. http://almacen1.ifeanet.org/publicacio nes/boletines/11(1-2)/11.pdf

Espinoza Soriano, Waldemar

1976 Las mujeres secundarias de Huayna Cápac: dos casos de señoralismo feudal en el Imperio Inca. Revista del Museo Nacional 42: 247-298. Lima.

Frisancho Pineda, David

1973 Medicina indígena y popular. Librería Editorial Juan Mejía Baca, Lima.

Garcilaso de la Vega, Inca

[1609] 1985 Comentarios Reales de los Incas, 2 tomos. Biblioteca Ayacucho, Caracas.

Gentile, Margarita E.

1991-1992 - La conquista incaica de la puna de Jujuy Notas a la crónica de Juan de Betanzos. Xama 4-5: 91-106. Mendoza: Universidad Nacional de Cuyo.

1996 Dimensión sociopolítica y religiosa de la capacocha del cerro Aconcagua. En: Boletín del Instituto Francés de Estudios Andinos 25 (1): 43-90. Lima.http://almacen2.ifeanet.org/publi caciones/boletines/25(1)/43.pdf

1997 Entre el derecho andino y el derecho espanol: la sucesión en el cacicazgo de los indios quilme reducidos en Buenos Aires. En: Revista de Historia del Derecho 25: 305-364. Instituto de Investigaciones de Historia del Derecho. Buenos Aires. Http://dialnet.unirioja.es

1998 El cacicazgo prehispánico de Marapa (Tucumán, siglos XVI-XVII). Ponencia leída ante las XVII Jornadas de Historia del Derecho Argentino. Instituto de Investigaciones de Historia del Derecho - Universidad Católica de Cuyo. San Luis.

1998 La pichca: oráculo y juego de fortuna (su persistencia en el espacio y tiempo andinos). Boletín del Instituto Francés de Estudios Andinos 27 (1): 75-131. Lima. http://almacen2.ifeanet.org/publicacio nes/boletines/27(1)/75.pdf

1999 Huacca Muchay - Religión Indígena. Religión, creencias, juegos. Área andina argentina, prehispánica, colonial, actual. Buenos Aires: Instituto Nacional Superior del Profesorado de Folklore.

2003 Dinámica de los oráculos andinos relacionados con el quehacer agropecuario. Ponencia leída ante el LIo Congreso Internacional de Americanistas, Santiago de Chile. En prensa.

2007ep. "Espacio y tiempo de un oráculo andino relacionado con el agro y la pesca. Nuevas evidencias". En: Adivinación y oráculos en el mundo andino antiguo (M.Curatola Petrocchi y Mariusz Ziolkowski, eds.). PUCP - IFEA, Lima.

2007ep. Tucumán: etnohistoria de un topónimo andino. Investigaciones y Ensayos, Academia Nacional de la Historia. Buenos Aires.

2007 "La madre de todos los tigres". En: Arkeos, Revista Electrónica de Arqueología PUCP. Vol. 2, nro. 1. Departamento de Humanidades, Pontificia Universidad Católica del Perú, Lima.

Gonçalez Holguín, Diego

[1608] 1952 Vocabulario de la lengua general de todo el Perú llamada lengua qquichua o del inca. Instituto de Etnología, Universidad Nacional Mayor de San Marcos, Lima.

Góngora Marmolejo, Alonso de

[1575] 1960 Historia de todas las cosas que han acaecido en el reino de Chile... [versión revisada por el p. Escobar]. Biblioteca de Autores Españoles 131: 77-226. Madrid.

González, Alberto R.

[1971] 1978 "El noroeste argentino y el área andina septentrional". En: Boletín de la Academia Nacional de Ciencias 52 (3-4): 373-404. Córdoba. 
González, Alberto R.

1977 Arte precolombino de la Argentina Introducción a su historia cultural. Filmediciones Valero, Buenos Aires.

Gordillo, José M., \& Del Río, Mercedes

1993 La visita de Tiquipaya (1573) - Análisis etno-demográfico de un padrón toledano. edición de los autores, Cochabamba.

Guaman Poma de Ayala, Felipe

[1613] 1980 El Primer Nueva Coronica y Buen Gobierno, 3 tomos. Siglo XXI, México.

Hocquenghem, Anne Marie \& Lyon, Pat

1980 A classs of anthropomorphic supernatural female in Moche iconographie. Nawpa Pacha 18: 27-50. Berkeley.

Hocquenghem, Anne Marie

1989 Iconografía Mochica. Lima: Pontificia Universidad Católica del Perú.

Holm, Olaf

1958 "Taptana o el ajedrez de Atahualpa: a los 425 años de Cajamarca". Cuadernos de Historia y Arqueología VIII (22-23. 24): 3-21. Casa de la Cultura Ecuatoriana, Guayaquil.

Hyslop, John \& Schobinger, Juan

1990 Establecimiento incaico en los nevados de Aconquija (Provincia Tucumán, Argentina). Gaceta Arqueológica Andina V: 67-75. Lima.

Levillier, Roberto

1921-1926 Información hecha en el Cuzco ... acerca de las costumbres que tenían los incas del Perú antes de la conquista española... in: Gobernantes del Perú. Cartas y Papeles del siglo XVI (R. Levillier, compilador), Madrid.

Levillier, Roberto

1928 Nueva Crónica de la conquista del Tucumán. 3 tomos. Lima - Varsovia.

Levillier, Roberto

1935-1942 Don Francisco de Toledo, supremo organizador del Perú. Su vida, su obra (15151582). 3 tomos. Buenos Aires: Ediciones del Congreso de la Nación.
Larrouy, Antonio

1923 Documentos del Archivo de Indias para la historia del Tucumán, Tomo Primero, 1591-1700. L.J.Rosso \& Cía, Impresores, Buenos Aires.

Lizondo Borda, Manuel, (compilador)

1936 - 1949 Documentos Coloniales relativos a San Miguel de Tucumán y a la Gobernación de Tucumán. 6 volúmenes. Junta Conservadora del Archivo Histórico de Tucumán, Tucumán.

Lyon, Pat

1979 Female supernaturals in ancient Peru. Nawpa Pacha 16: 95-140. Berkeley.

Magrassi, Guillermo \& Rocca, Manuel

Sin fecha. Instrucciones para el juego de la Yagua, en: Los chiriguano chané en la Argentina. ms. Http://www.suteba.org.ar

Matienzo, Juan de

[1567] 1967 Gobierno del Perú. Instituto Francés de Estudios Andinos, Lima.

Moussy, V.Martín de

1860 Description Géographique et Statistique de la Conféderation Argentine. 5 tomos. Librairie de Firmin Didot Frères, Fils et Cie., Paris.

Murra, John V.

1972 "El "control vertical" de un máximo de pisos ecológicos en la economía de las sociedades andinas". En: Visita de la provincia de León de Huánuco en 1562. Tomo II: 429-468. Universidad Nacional Hermilio Valdizán, Huánuco.

Murúa, Martín

[1613] 1986 Historia General del Perú. Historia 16. Madrid.

Nardi, Ricardo L.J.

1979 "El kakán, lengua de los diaguitas". En: Sapiens 3: 1-33. Chivilcoy.

Pizarro, Pedro

[1571] 1978 Relación del descubrimiento y conquista de los reinos del Perú. Pontificia Universidad Católica del Perú, Lima.

Ramos Gavilán, Alonso

[1621] 1976 Historia de Nuestra Señora de Copacabana. Academia Boliviana de la Historia, La Paz. 
Romero, Emilia

1943 Juegos del Antiguo Perú. contribución a una historia del juego en el Perú. México: Ediciones Llama.

Rostworowski, María

1978 Señoríos indígenas de Lima y Canta. Instituto de Estudios Peruanos, Lima.

Sempé, Carlota \& Gentile, Margarita E.

2004 Análisis de microsecuencias narrativas en la alfarería de La Aguada, área andina argentina. En: CD XV Congreso Nacional de Arqueología Argentina. Universidad Nacional de Río IV. Río Cuarto. Versión en: www.ucm.es/info/especulo/numero33/microse c.html

Toledo, Francisco de

[1570-1575] 1975 Tasa de la Visita General de..., 339p., Universidad Nacional Mayor de San Marcos. Lima.

Torre Revello, José

1943 Esteco y Concepción del Bermejo, dos ciudades desaparecidas. Facultad de
Filosofía y Letras UBA, Buenos Aires.

Varón Gabai, Rafael

1993 "Estategias políticas y relaciones conyugales. El comportamiento de incas y españoles en Huaylas en la primera mitad del siglo XVI". Boletín del Instituto Francés de Estudios Andinos 22 (3): 721-737.Lima.

Vivante, Armando

1944 "Un juego de azar indígena". Revista Geográfica Americana XXI (127): 213-216. Buenos Aires.

Westerveld, Govert

2004 La reina Isabel La Católica: Su reflejo en la dama poderosa de Valencia, cuna del Ajedrez moderno y origen del juego de Damas. Valencia: Generalitat Valenciana. 